Gardarsdottir, H., Egberts, T.C.G., Dijk, L. van, Heerdink, E.R. Seasonal patterns of initiating antidepressant therapy in general practice in the Netherlands during 2002-2007. Journal of Affective Disorders: 2010, I22(3) 208-212

\begin{tabular}{|l|l|}
\hline $\begin{array}{l}\text { Postprint } \\
\text { Version }\end{array}$ & 1.0 \\
\hline Journal website & $\underline{\text { http://dx.doi.org/10.1016/j.jad.2009.06.033 }}$ \\
\hline Pubmed link & $\underline{\text { http://www.ncbi.nlm.nih.gov/pubmed/19733914 }}$ \\
\hline DOI & $10.1016 /$ j.jad.2009.06.033 \\
\hline
\end{tabular}

This is a NIVEL certified Post Print, more info at http://www.nivel.eu

\title{
Seasonal patterns of initiating antidepressant therapy in general practice in the Netherlands during 2002-2007
}

\author{
HELga GARDARSDOtTIR ${ }^{\mathrm{A}}$, TOINE C.G. EGBERTS ${ }^{\mathrm{A}, \mathrm{B}}$, LISET VAN DIJK $^{\mathrm{A}, \mathrm{C}}$ AND EIBERT R. HEERDINK $^{\mathrm{A}, \mathrm{B}}$, \\ ${ }^{a}$ Division of Pharmacoepidemiology and Pharmacotherapy, Utrecht Institute for Pharmaceutical Sciences, \\ Faculty of Science, Utrecht University, Utrecht, The Netherlands \\ ${ }^{\mathrm{b}}$ Department of Clinical Pharmacy, University Medical Centre Utrecht, Utrecht, The Netherlands \\ ${ }^{c}$ NIVEL (Netherlands Institute for Health Services Research), Utrecht, The Netherlands
}

\begin{abstract}
Background: Studies on seasonality in antidepressant prescribing showed prescribing peaks during autumn and winter. Since then, new antidepressants have become available and indications have broadened, possibly contributing to a change in prescribing practices. This study investigates seasonal patterns of initiating antidepressant use in general practice during 2002-2007 in the Netherlands.

Method: Data were obtained from the Netherlands Information Network of General Practice. The study population was composed of adult patients initiating antidepressant use from 21 December 2001 to 20 December 2007, with no antidepressant use during at least two years prior to initiation. Seasonal distribution of initiating antidepressant use was investigated for the four seasons. The difference in frequency of initiating use between the seasons, normalized for general practice contacts, was tested using Chi-square testing.

Results: The majority of the study population $(\mathrm{N}=16,289)$ was female $(64.0 \%)$ with a mean age (standard deviation (SD)) of $50.5(18.0)$ years. Significant seasonal variation $(\mathrm{p}<0.01)$ was found in initiation of antidepressant use, with about $5-35 \%$ more patients initiating use during winter than summer. Significant $(p<0.01)$ seasonality of initiating antidepressant use was seen in all patient groups, except within age groups 18-30 years and $>60$ years.

Limitations: Our study investigated only general practitioner prescribing thus additional prescriptions from psychiatrists are missed.

Conclusions:The seasonal influence on initiation of antidepressant drug use has not changed with the introduction of the newer antidepressants and is in line with seasonality of depression onset, with most patients initiating use during the winter and fewest during the summer.
\end{abstract}

\section{INTRODUCTION}

Research has shown that human functioning and well being can be influenced by the seasons and seasonality in mood disorders has been studied extensively. Seasonal affective disorder (SAD) is a wellknown and widely described phenomenon ([Rosenthal et al., 1984], [Oyane et al., 2005], [Magnusson, 2000], [Mersch et al., 1999], [Molin et al., 1996] and [Rastad et al., 2005]). It is characterized by recurrent depression during winter and autumn seasons with remission in the spring or summer for at least two successive years ([Rosenthal et al., 1984] and [Partonen and Lonnqvist, 1998]). Seasonal patterns have also 
Gardarsdottir, H., Egberts, T.C.G., Dijk, L. van, Heerdink, E.R. Seasonal patterns of initiating antidepressant therapy in general practice in the Netherlands during 2002-2007. Journal of Affective Disorders: 2010 1 $122(3)$ 208-212

been documented for onset of depressive episodes in both general practice patients and hospitalized patients suffering from unipolar depression, showing a large peak during the winter ([Sato et al., 2006] and [Blacker et al., 1997]). Other studies have shown seasonal variation in bipolar disorder admissions, with fewer depression admissions during summer time (Lee et al., 2007), and shorter duration of hospitalization for depressed female patients during the summer (Kecskes et al., 2003). In 1981, Williams and Dunn investigated the cyclic variation in psychotropic drug prescribing (Williams and Dunn, 1981). They described a four monthly cycle for antidepressant drug prescribing, with peaks in February, May and October. A few years later, Skegg et al. (1986) reported that most antidepressant users in the community initiate use during the autumn months and the least during the summer months. Further, Balestrieri et al. (1991) showed seasonality in the amount of defined daily doses (DDDs) of antidepressants prescribed in general practice. Since then, many new antidepressants have become available and indications for antidepressant drug prescribing have broadened (Meijer et al., 2004). How these changes in prescribing practices might have influenced the seasonal patterns of prescribing and if seasonality in prescribing complies with seasonality of depression is yet to be investigated.

The aim of this study was to investigate if there is a seasonal pattern of initiating antidepressant drug treatment in general practice during 2002-2007 in the Netherlands.

\section{METHODS}

\subsection{Setting and study population}

Data were obtained from the Netherlands Information Network of General Practice (LINH) (Verheij et al., 2009). LINH is a network of 90 general practices with around 350,000 registered patients, which have actively collected health care data for research purposes since 2001. The LINH GPs register information on all health problems presented within a consultation including information on referrals to specialist care and prescribed medicines in a standardized manner. The LINH database includes information on patient gender, date of birth and clinical diagnoses which are coded using the ICPC scheme (International Classification of Primary Care) (Lamberts and Wood, 1987). Prescriptions prescribed by the general practitioner are registered in a separate database including information on drug name, date of prescribing and amount prescribed. Drugs are coded according to the Anatomical Therapeutic Chemical (ATC) classification (Anon, 2009). Each patient is identified with an anonymous unique patient-identification code. Patients are representatives for the Dutch population with respect to age and gender.

For this study, patients 18 years and older who received their first antidepressants at any time from 21 December 2001 to 20 December 2007 were identified from LINH. This specific study period was selected to follow the seasonal division of the year, from winter (21 December 2001-20 March 2002) until autumn (21 September-20 December 2007). All patients had to be registered for at least two years in the LINH prior to receiving their first antidepressant. The date of a first prescribed antidepressant prescription for each patient was set as start date and patients were not allowed to have used any antidepressants during two years prior to start date.

\subsection{Data analysis}

The primary outcome was the seasonal distribution of initiating antidepressant treatment. The distribution of the outcome (patient start date) was investigated for the four seasons (winter: December 21-March 20, spring: March 21-June 20, summer: June 21-September 20, autumn: September 21-December 20). Each study year was composed of the four seasons and defined as running from 21 December until 20 December. For each year the proportion of patients initiating antidepressant therapy per season was assessed. In case of no seasonality, $25 \%$ of patients each year were expected to initiate antidepressant drug use during each season.

General practice contacts might be subject to seasonal variations as during the holiday periods less frequent contacts are to be expected. To account for this variation, the seasonal variance of general practice contacts was assessed. Subsequently, the proportion of patients initiating antidepressant drug use per season was normalized for the seasonal variation in general practice contacts. The normalization was performed by investigating the frequency of general practice contacts per season for the study period. General practice contacts were least frequent during the summer, thus summer was denoted with an adjustment factor of 1.0. The other seasons all received an adjustment factor based on how more frequent the contacts were per season when compared to summer, thus if contacts during autumn were $20 \%$ higher than during summer, 
Gardarsdottir, H., Egberts, T.C.G., Dijk, L. van, Heerdink, E.R. Seasonal patterns of initiating antidepressant therapy in general practice in the Netherlands during 2002-2007. Journal of Affective Disorders: 2010 I $22(3)$ 208-212

autumn would receive an adjustment factor of 1.20. The adjustment factors were used to normalize the proportion of patients initiating antidepressant drug use.

The significance of seasonal variation in initiating antidepressant drug use, when normalized for seasonal variation in general practice contacts, was tested using the Chi-square test. Seasonal distribution of initiating antidepressant drug use was investigated for the total study population but also stratified for gender, age group (18-30 years, 31-45 years, 46-60 years and $>60$ years) and type of antidepressant treatment therapy. Antidepressant treatment therapy was divided into three groups, namely, tricyclic antidepressants (TCA; desipramine, imipramine, clomipramine, trimipramine, amitriptyline, nortriptyline, doxepin, dosulepin, maprotiline), selective serotonin reuptake inhibitors (SSRI; fluoxetine, citalopram, paroxetine, sertraline, fluvoxamine, escitalopram) and other antidepressants (phenelzine, tranylcypromine, moclobemide, mianserin, trazodone, nefazodone, mirtazapine, venlafaxine, duloxetine). Seasonal distribution of initiating antidepressant drug use in patients who received a single antidepressant prescription and those who receive at least two prescriptions during the 12 months from start date was investigated separately. Patients who receive a single antidepressant prescription from the general practitioner often do not initiate therapy or discontinue use within two weeks (van Geffen et al., 2009) thus the depressive symptom severity between the two groups might differ. In these two patient groups, the seasonal distribution in initiating antidepressant drug use was investigated from winter 2002 to autumn 2006, as those who initiate use in 2007 could not be followed for 12 months. Data analysis was performed using SPSS for Windows release 14.0 (SPSS Inc. Chicago, IL).

\section{RESULTS}

The study population $(N=16,289)$ was predominantly female $(64.0 \%)$ with a mean age (SD) of 50.5 (18.0) years (Table 1). Roughly half of the antidepressant drug users were prescribed an SSRI on start date (53.4\%).

\section{[TABLE 1.]}

The seasonal variation in initiating antidepressant drug use from winter 2002 to autumn 2007, nonnormalized and normalized for seasonal variation in general practice contacts, is displayed in Fig. 1. For the non-normalized analysis the peaks in use were mostly seen during the winter or autumn season. When the results were normalized for seasonal variation in general practice contacts most annual new antidepressant drug users initiated use during the winter season. For the normalized analysis, there was a 5-35\% difference in the amount of antidepressant drug users who initiate antidepressant drug use during summer or winter, apart from in 2002 where proportion of starters initiating use during winter and summer is similar. Table 1 additionally presents the total proportion of antidepressant starters who initiate antidepressant drug use during each season, normalized for seasonal variation in general practice contacts. The total proportion that initiates antidepressant drug use per season is presented for the total study population and the different patient characteristics. Statistically significant difference $(p<0.01)$ is seen in initiating antidepressant drug use between the seasons in both men and women, with most initiating use during the winter season. The same was seen in antidepressant initiators in age groups 30-45 and 46-60 years, and those who got a TCA or an SSRI on start date. In both patients who received a single antidepressant prescription and in those who received at least two antidepressant drug prescriptions in 12 months we found statistically significant seasonal differences $(p<0.01)$ in initiating antidepressant drug use, with most patients starting during the winter.

\section{DisCUSSION}

We found a significant difference in amount of patients who initiate antidepressant drug use between the seasons, with 5-35\% more patients initiating antidepressant drug use during the winter when compared to summer. Prior studies report highest use of antidepressants during the autumn or winter months and lowest during the summer months ([Williams and Dunn, 1981], [Skegg et al., 1986] and [Balestrieri et al., 1991]). Our finding of the least amount of patients initiating use during the summer months is in accordance with their results. However, for most years we find the largest peaks in use during the winter months and not during autumn as they report. The reason for this might be that in our analysis we normalized for seasonal variation in general practice contacts. In the non-normalized analysis we found peaks of antidepressant 
Gardarsdottir, H., Egberts, T.C.G., Dijk, L. van, Heerdink, E.R. Seasonal patterns of initiating antidepressant therapy in general practice in the Netherlands during 2002-2007. Journal of Affective Disorders: 2010 I $22(3)$ 208-212

initiators during the autumn months. We found that most general practice contacts take place during the autumn. The seasonal variation presented by the non-normalized analysis might therefore include at least two seasonality components. Firstly, the seasonal influence of initiating antidepressant drug use due to seasonal difference in general practice visit frequency and secondly, the seasonal influences of antidepressant drug prescribing. The normalized analysis shows that most antidepressant drug users initiate use during the winter season. This is in line with what Blacker et al. (1997) have reported for seasonality in depression onset. They interviewed and screened about 2200 consecutive patients in general practice and found the highest incidence of depression during the winter months. Evidently, the seasonal peaks in initiating antidepressant use apparent from our analysis are strongly related to the more frequent presentation of depressive symptoms during winter.

\section{[FIGURE 1]}

The stratified analysis showed seasonal differences in initiating antidepressant drug use for almost all characteristics. However, in patients above 60 years no seasonality was found. These findings confirm what has been reported on depressive symptoms in the elderly (de Craen et al., 2005). The SSRIs are most frequently prescribed for treating depression (Gardarsdottir et al., 2007) and therefore more seasonal variance was expected in this group of patients. In the SSRI group a peak in initiation was seen during the winter season while similar amount of patients initiated use during the spring, summer and autumn seasons. The TCA users, however, represent a more heterogeneous group, i.e., more severely depressed patients where strong seasonality would be expected and patients treated for non-psychiatric indications where seasonal pattern would not be expected. The seasonal pattern of TCA initiators displayed the least amount of patients initiating use during summer with gradual increase and a peak in initiations during the winter. Patients who used other types of antidepressant (not a TCA or an SSRI) did not show significant seasonality in initiating use. The reason might be that although these antidepressants are indicated to treat depression few of them are considered as first choice when treating depression. The introduction of the newer antidepressants has not resulted in differences with regard to seasonality in initiation, as both the old and the new show peaks during the winter season.

The significant difference we found in the amount of antidepressant initiators per season is of methodological importance for pharmacoepidemiologic studies. It is likely to be of importance for prevalence and incidence measurements, as well as for patient sampling in some study designs such as cross sectional, case-control and case-crossover studies.

The strength of our study is the large amount of general practice patients investigated and the long follow up time. Our study is bound by the limitation that we only investigated general practice prescriptions. The patients included in our study might undergo treatment by a psychiatrist or have been admitted to closed care facilities where therapy was already started. We, however, think that this only applies to a very small part of the study population as over $80 \%$ of patients receive their first antidepressant prescription from a general practitioner (Gardarsdottir et al., 2009). Another limitation is that we did not investigate seasonality in prescribing practices of the general practitioners. If severity of depression could be estimated, i.e., by using a validated depressive symptom rating scale, it would be possible to investigate if reported depressive symptoms of patients who visit the general practitioner during the summer season might be considered more severe than if they would present the same symptoms during the winter season. This would lead to more easily prescribing of antidepressants during the summer season. On the other hand, the general practitioner might see less reason for treating mild depression symptoms with antidepressants during the summer time than during winter time. In this study we investigated patients who receive at least two antidepressant prescriptions in 12 months and those who receive only a single antidepressant prescription. Although both patient groups showed a significant peak during winter, patients who receive a single antidepressant prescription seem to initiate use during the autumn more frequently than those who receive at least two prescriptions. A study on general practice patients who receive only a single antidepressant prescription showed that around $4 \%$ of the patients do not get it dispensed from the pharmacy and of those who initiate use many discontinue within two weeks (van Geffen et al., 2009). Patients who receive at least two antidepressant prescriptions are therefore considered to suffer from more serious symptoms while more uncertainty is of symptom severity in those who only receive a single antidepressant prescription. The difference in seasonal pattern of initiation between the two groups might indicate that there is a seasonal component in antidepressant drug prescribing practices of the general practitioner. 
Gardarsdottir, H., Egberts, T.C.G., Dijk, L. van, Heerdink, E.R. Seasonal patterns of initiating antidepressant therapy in general practice in the Netherlands during 2002-2007. Journal of Affective Disorders: 2010 122(3) 208-212

In conclusion, initiation of antidepressant drug use is influenced by seasonality with most patients initiating use during the winter and fewest during the summer. The introduction of the newer antidepressants did not change the seasonal patterns already reported in earlier studies. The winter peaks are in line with what is seen in depression onset in general practice.

\section{ROLE OF FUNDING SOURCE}

Funding for this study was provided by the division of Pharmacoepidemiology and Pharmacotherapy (Utrecht University). The division of Pharmacoepidemiology and Pharmacotherapy employing authors HG, LvD, TCE and ERH has received unrestricted funding for pharmacoepidemiological research from GlaxoSmithKline, Novo Nordisk, the private-public funded Top Institute Pharma (http:// www.tipharma.nl, includes co-funding from universities, government, and industry), the Dutch Medicines Evaluation Board, and the Dutch Ministry of Health. The funding source had no influence on study design; collection, analysis, and interpretation of data; the writing of the report; or the decision to submit the paper for publication.

\section{CONFLICT OF INTEREST}

There was no conflict of interest when undertaking this study.

\section{REFERENCES}

Anon, 2009 Anon, Anatomical Therapeutic Chemical (ATC) Classification Index [online] (2009) Available from http://www.whocc.no [Accessed 1 February 2009].

Balestrieri et al., 1991 M. Balestrieri, N. Bragagnoli and C. Bellantuono, Antidepressant drug prescribing in general practice: a 6-year study, J. Affect. Disord. 21 (1991), pp. 45-55.

Blacker et al., 1997 C.V. Blacker, J.M. Thomas and C. Thompson, Seasonality prevalence and incidence of depressive disorder in a general practice sample: identifying differences in timing by caseness, J. Affect. Disord. 43 (1997), pp. 41-52.

de Craen et al., 2005 A.J. de Craen, J. Gussekloo, R.C. van der Mast, S. le Cessie, J.W. Lemkes and R.G. Westendorp, Seasonal mood variation in the elderly: the Leiden 85-plus study, Int. J. Geriatr. Psychiatry 20 (2005), pp. 269-273.

Gardarsdottir et al., 2007 H. Gardarsdottir, E.R. Heerdink, L. van Dijk and A.C. Egberts, Indications for antidepressant drug prescribing in general practice in the Netherlands, J. Affect. Disord. 98 (2007), pp. 109-115.

Gardarsdottir et al., 2009 H. Gardarsdottir, E.C. van Geffen, J.J. Stolker, T.C. Egberts and E.R. Heerdink, Does the length of the first antidepressant treatment episode influence risk and time to a second episode?, J. Clin. Psychopharmacol. 29 (2009), pp. 69-72.

Kecskes et al., 2003 I. Kecskes, Z. Rihmer, K. Kiss, A. Vargha, I. Szili and A. Rihmer, Possible effect of gender and season on the length of hospitalisation in unipolar major depressives, J. Affect. Disord. 73 (2003), pp. 279-282.

Lamberts and Wood, $1987 \mathrm{H}$. Lamberts and M. Wood, International Classification of Primary Care, Oxford University Press, Oxford (1987).

Lee et al., 2007 H.C. Lee, S.Y. Tsai and H.C. Lin, Seasonal variations in bipolar disorder admissions and the association with climate: a population-based study, J. Affect. Disord. 97 (2007), pp. 61-69.

Magnusson, 2000 A. Magnusson, An overview of epidemiological studies on seasonal affective disorder, Acta Psychiatr. Scand. 101 (2000), pp. 176-184.

Meijer et al., 2004 W.E. Meijer, E.R. Heerdink, H.G. Leufkens, R.M. Herings, A.C. Egberts and W.A. Nolen, Incidence and determinants of long-term use of antidepressants, Eur. J. Clin. Pharmacol. 60 (2004), pp. $57-61$.

Mersch et al., 1999 P.P. Mersch, H.M. Middendorp, A.L. Bouhuys, D.G. Beersma and R.H. van den Hoofdakker, The prevalence of seasonal affective disorder in The Netherlands: a prospective and retrospective study of seasonal mood variation in the general population, Biol. Psychiatry 45 (1999), pp. 1013-1022.

Molin et al., 1996 J. Molin, E. Mellerup, T. Bolwig, T. Scheike and H. Dam, The influence of climate on development of winter depression, J. Affect. Disord. 37 (1996), pp. 151-155.

Oyane et al., 2005 N.M. Oyane, F. Holsten, R. Ursin and B. Bjorvatn, Seasonal variations in mood and behaviour associated with gender, annual income and education: the Hordaland Health Study, Eur. J. Epidemiol. 20 (2005), pp. 929-937. 
Gardarsdottir, H., Egberts, T.C.G., Dijk, L. van, Heerdink, E.R. Seasonal patterns of initiating antidepressant therapy in general practice in the Netherlands during 2002-2007. Journal of Affective Disorders: 2010 I $22(3)$ 208-212

Partonen and Lonnqvist, 1998 T. Partonen and J. Lonnqvist, Seasonal affective disorder, Lancet 352 (1998), pp. 1369-1374.

Rastad et al., 2005 C. Rastad, P.O. Sjoden and J. Ulfberg, High prevalence of self-reported winter depression in a Swedish county, Psychiatry Clin. Neurosci. 59 (2005), pp. 666-675.

Rosenthal et al., 1984 N.E. Rosenthal, D.A. Sack, J.C. Gillin, A.J. Lewy, F.K. Goodwin, Y. Davenport, P.S. Mueller, D.A. Newsome and T.A. Wehr, Seasonal affective disorder. A description of the syndrome and preliminary findings with light therapy, Arch. Gen. Psychiatry 41 (1984), pp. 72-80.

Sato et al., 2006 T. Sato, R. Bottlender, M. Sievers and H.J. Moller, Distinct seasonality of depressive episodes differentiates unipolar depressive patients with and without depressive mixed states, J. Affect. Disord. 90 (2006), pp. 1-5.

Skegg et al., 1986 K. Skegg, D.C. Skegg and B.W. McDonald, Is there seasonal variation in the prescribing of antidepressants in the community?, J. Epidemiol. Community Health 40 (1986), pp. 285-288.

van Geffen et al., 2009 E.C. van Geffen, H. Gardarsdottir, R. van Hulten, L. van Dijk, A.C. Egberts and E.R. Heerdink, Initiation of antidepressant therapy: do patients follow the GP's prescription?, Br. J. Gen. Pract. 59 (2009), pp. 81-87.

Verheij et al., 2009 R.A. Verheij, J.H.M. Te Brake, H. Abrahamse, H. Van den Hoogen, J. Braspenning and T. Van Althuis, Landelijk Informatienetwerk Huisartsenzorg. Feiten en cijfers over huisartsenzorg in Nederland [National Information Network of Family Practices, Facts and Figures of the Care of Family Practitioners in the Netherlands] [online] (2009) Available from http://www. www.linh.nl [Accessed 25 April 2009].

Williams and Dunn, $1981 \mathrm{P}$. Williams and G. Dunn, Cyclical variation in psychotropic drug prescription, J. Epidemiol. Community Health 35 (1981), pp. 136-138.

Corresponding author. Division of Pharmacoepidemiology and Pharmacotherapy, Utrecht Institute for Pharmaceutical Sciences, Faculty of Science, Utrecht University, PO Box 80082, 3508 TB Utrecht, The Netherlands. Tel.: +31 30 2537324; fax: +31 302539166 .

\section{TABLES AND FIGURES}

Table 1

Characteristics of the study population on start date $(N=16,289)$ and proportion of antidepressant drug initiators per season stratified by patient characteristics.

\begin{tabular}{|c|c|c|c|c|c|c|c|}
\hline & \multicolumn{2}{|l|}{ Total } & \multirow[t]{2}{*}{ Winter } & \multirow[t]{2}{*}{ Spring } & \multirow[t]{2}{*}{ Summer } & \multirow[t]{2}{*}{ Autumn } & \multirow{2}{*}{$\frac{\text { Chi-square }}{p}$} \\
\hline & $N$ & $\%$ & & & & & \\
\hline All users & 16,289 & & 0.274 & 0.241 & 0.238 & 0.247 & $<0.01$ \\
\hline \multicolumn{8}{|l|}{ Gender } \\
\hline Female & 10,426 & 64.0 & 0.275 & 0.245 & 0.236 & 0.244 & $<0.01$ \\
\hline Male & 5863 & 36.0 & 0.271 & 0.234 & 0.243 & 0.252 & $<0.01$ \\
\hline \multicolumn{8}{|l|}{ Age } \\
\hline $18-30$ years & 2250 & 13.8 & 0.266 & 0.231 & 0.244 & 0.259 & 0.08 \\
\hline $31-45$ years & 4881 & 30.0 & 0.282 & 0.233 & 0.234 & 0.251 & $<0.01$ \\
\hline $46-60$ years & 4586 & 28.1 & 0.284 & 0.247 & 0.224 & 0.245 & $<0.01$ \\
\hline$>60$ years & 4572 & 28.1 & 0.259 & 0.249 & 0.254 & 0.238 & 0.23 \\
\hline \multicolumn{8}{|l|}{ Type of antidepressant } \\
\hline TCA & 5088 & 31.2 & 0.271 & 0.240 & 0.233 & 0.256 & $<0.01$ \\
\hline SSRI & 8693 & 53.4 & 0.278 & 0.238 & 0.243 & 0.241 & $<0.01$ \\
\hline Other $^{a}$ & 2508 & 15.4 & 0.265 & 0.254 & 0.232 & 0.249 & 0.11 \\
\hline \multicolumn{8}{|c|}{ Number of antidepressant prescriptions } \\
\hline $1 \mathrm{AD}$ prescription ${ }^{\mathrm{b}}$ & 4307 & 31.1 & 0.272 & 0.242 & 0.232 & 0.254 & $<0.01$ \\
\hline$>1 \mathrm{AD}$ prescriptions ${ }^{\mathrm{b}}$ & 9997 & 68.9 & 0.275 & 0.240 & 0.242 & 0.243 & $<0.01$ \\
\hline
\end{tabular}

The proportions are normalized for seasonal variation in general practice contacts.

a Phenelzine, tranylcypromine, moclobemide, mianserin, trazodone, nefazodone, mirtazapine, venlafaxine, duloxetine.

b Proportion of patients who initiate use during 2002-2006 $(N=14,304)$, as those who initiate use in 2007 do not all have 12 months of follow up time. 
Fig. 1. Proportion of patients who initiate antidepressant drug use per season, during 2002-2007. The dotted line (---O---) represents new initiators per season not

normalized for variation in general practice contacts while the solid line $(-\bullet-)$ represents new initiators per season normalized for variation in general practice contacts.

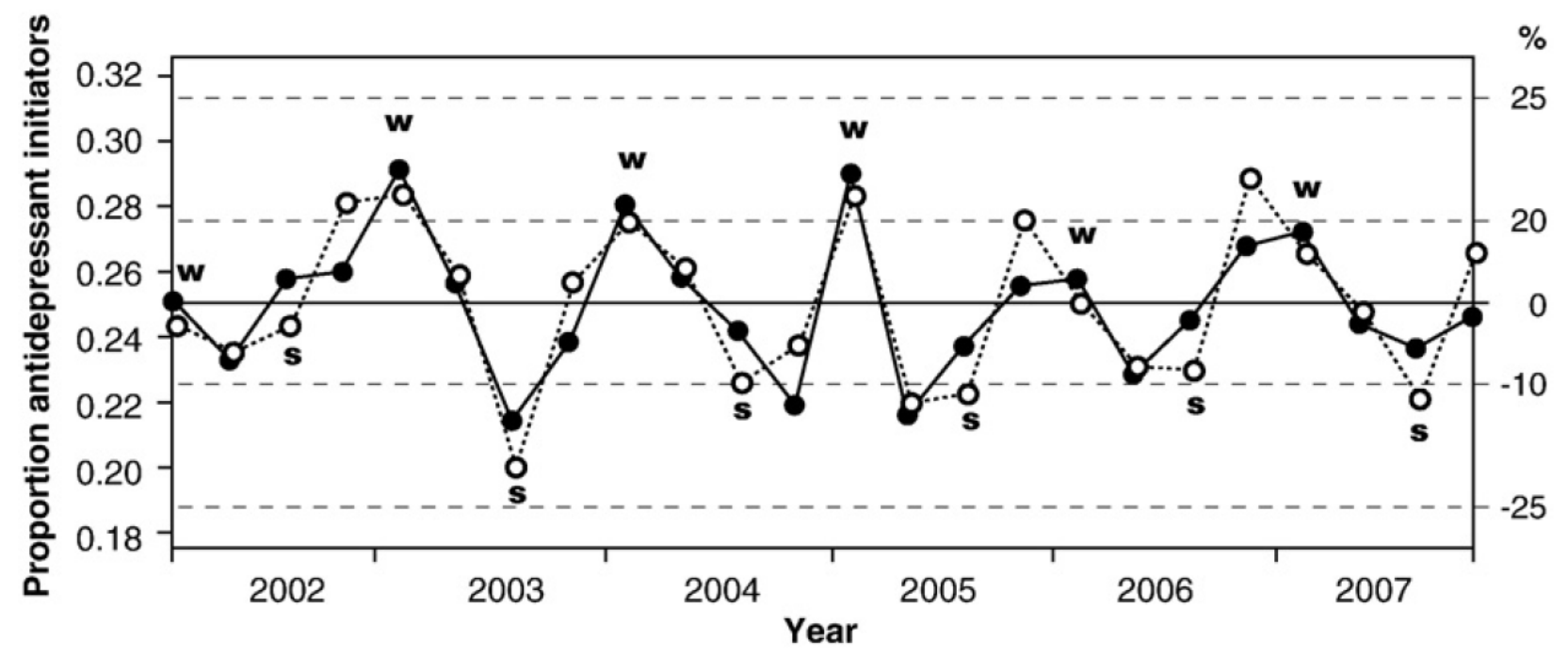

